\title{
Recovery of Terephthalic Acid by employing magnetic nanoparticles as a solid support
}

\author{
Elmira Ghamary', Mir Mohammad Alavi Nikje ${ }^{1 *}$, Seyedeh Leila Rahmani Andabil' ${ }^{1}$ and Lida Sarchami ${ }^{1}$ \\ 'Department of Chemistry, Faculty of Science, Imam Khomeini International University, Qazvin, Iran \\ *drmm.alavi@gmail.com
}

\begin{abstract}
The aim of this research work is focused on the improvement of Terephthalic acid recovery from PET wastes by using organically modified nano- $\mathrm{Fe}_{3} \mathrm{O}_{4} @$ Cyanuric Chloride as the solid support. The performance of organically modified nano magnetic was examined in detail and the obtained results were compared with the unsupported reaction data. Required reaction time for complete glycolysis of the wastes, consumption of the solvent as well as catalyst decreases up $99 \%, 37.5 \%$ and $40 \%$ respectively. Result showed that nano- $\mathrm{Fe}_{3} \mathrm{O}_{4} @$ Cyanuric Chloride delivered good performance as solid support in depolymerizing of PET to the terephthalic acid.
\end{abstract}

Keywords: poly (ethylene terephthalate), recycling, solid support, terephthalic acid.

\section{Introduction}

The use of polymer in various application are expanded daily and PET is one of the most consumed polymers as its excellent thermal and mechanical properties. This polymer used in the manufacture of high strength fibers, soft drink bottles and photographic films and at the end of the last century its consumption increased to more than $3,000,000$ tons per year ${ }^{[1]}$. In 2009 the global consumption of PET packaging was almost $15.5 \mathrm{Mt}$ while the estimate is to growth to almost $19 \mathrm{Mt}$ by $2017-$ a $5.2 \%$ increase per annum. By increasing in PET production and since this polymer is not biodegradable, big waste stream create a serious environmental problem each year. Chemical recycling of PET has been attracting attention for both environmental and economic reasons ${ }^{[2]}$.

In this case, Nikje and Nazari ${ }^{[3]}$ and his coworker reported glycolyzing of PET by using methanol, ethanol, 1-butanol, 1-pentanol, and 1-hexanol in the presence of different simple basic catalysts, namely, potassium hydroxide, sodium hydroxide and etc, under microwave irradiation. Pingale and Shukla ${ }^{[4]}$ research group had been used zinc acetate, sodium carbonate, sodium bicarbonate and barium hydroxide as catalyst for glycolysis PET by using microwave as energy source. In our previously reported data, we glycolized PET by using DEG as the solvent and $\mathrm{NaOH}$ as the catalysts under microwave irradiation ${ }^{[5]}$. Parab et al. ${ }^{[6]}$ used ethanolamine for aminolytic depolymerization of PET bottles wastes with heterogeneous, recyclable acid catalysts such as beta zeolite and montmorillonite KSF under microwave irradiation. Siddiqui ${ }^{[2]}$ reported the using of microwave irradiation as a convenient energy source for recycling of poly (ethylene terephthalate) waste through methanolic pyrolysis. Chen et al. ${ }^{[7]}$ glycolized PET by using excess ethylene glycol (EG) in the presence of zinc acetate as catalysts under microwave irradiation. The glycolysis of PET has been reported by using monoetylene glycol (MEG), diethylen glycol (DEG), monopropylene glycol (MPG) and dipropylene glycol (DPG) in present zinc acetate as catalyst under microwave irradiation ${ }^{[8]}$. Chaudhary et al. ${ }^{[9]}$ glycolized PET and produced BHET for preparation of polyester polyols under microwave irradiation. Chemical depolymerization of PET complex was done by Liu et al. ${ }^{[10]}$. Waste depolymerization of PET was done by using bransted acidic ionic liquid under microwave irradiation ${ }^{[11]}$ and in another report PET was glycolized by using several ionic liquids and basic ionic liquids as catalysts ${ }^{[12]}$. In addition the efficiency of Metal-Containing Ionic Liquids as a highly Effective Catalysts for Degradation of Poly (Ethylene Terephthalate) has been surveyed ${ }^{[13]}$. All the mentioned catalysts such as alkalies, metal acetate, zeolites, ionic liquids and etc, in the PET glycolysis reactions required long reaction times and contributed low BHET and TPA yields. In order to resolve these drawbacks and improve reaction conditions Imran et al. ${ }^{[14,15]}$ used thermally stable and highly selective silica nanoparticle-supported metal (Mn, Zn, Ce) oxides as the catalysts for PET depolymerization. After that, Park et al. ${ }^{[16]}$ outstretch graphene oxide and manganese oxide as the catalysts for PET glycolysis. Bartolome et al. ${ }^{[17]}$ used nano- $\gamma-\mathrm{Fe}_{2} \mathrm{O}_{3}$ as an easily recoverable catalyst for the recycling of PET. The number of active sites in nanoscale catalysts increase and also changing inherent properties of the catalysts in nanoscale usually leads to better catalytic performance.

In continuation of our previous work on PET chemical recycling ${ }^{[3,5]}$ we decided to examine the performance of nano- $\mathrm{Fe}_{3} \mathrm{O}_{4} @$ Cyanuric Chloride as the reagent-solid support in order to recovery TPA from the bottles wastes. By using of this reagent-solid support required time to access to high recovery yield significantly decreases so that is comparable with microwave method. 


\section{Experimental}

\subsection{Preparation of nano- $\mathrm{Fe}_{3} \mathrm{O}_{4} @$ Cyanuric Chloride}

The magnetic nanoparticles $\left(\mathrm{Fe}_{3} \mathrm{O}_{4}, 0.5 \mathrm{~g}\right)$ were dispersed in the Acetonitrile $(100 \mathrm{~mL})$ with sonication $(20 \mathrm{~min})$. Then Cyanuric Chloride ( $0.4 \mathrm{~g}$ ) was added to the mixture and mechanically stirred at room temperature $(7 \mathrm{~h})$. Finally, the core-shell nanoparticles were separated from the reaction medium, and washed with Acetonitrile for two times and then dried at $45^{\circ} \mathrm{C}$ in oven overnight and characterized ${ }^{[18]}$.

\subsection{PET glycolysis using nano- $\mathrm{Fe}_{3} \mathrm{O}_{4} @ C y a n u r i c$ Chloride and $\mathrm{NaOH}$}

For depolymerization, in a three-necked flask, $100 \mathrm{~mL}$ round-bottom glass equipped with a condenser, thermometer and magnetic stirrer PET flakes ( $1 \mathrm{~g}$ ) was treated with diethylene glycol using different PET: DEG molar ratios (1:4 to 1:8) at $160^{\circ} \mathrm{C}$. The used $\mathrm{NaOH}$ and $\mathrm{Fe}_{3} \mathrm{O}_{4} @$ Cyanuric Chloride were (0.1-0.5 g) and (0.01-0.3 g), respectively. At the end of the reaction, distilled water $(70 \mathrm{~mL})$ was added to the reaction mixture with vigorous agitation. Then the TPA in the mixture was precipitated by bringing the $\mathrm{pH}$ to 2-3 by addition of $\mathrm{HCl}$ and dried at $80^{\circ} \mathrm{C}$ in the oven $(1 \mathrm{~h})$, characterized and data compared with an authentic sample.

\section{Results and discussion}

\subsection{Nano- $\mathrm{Fe}_{3} \mathrm{O}_{4} @$ Cyanuric Chloride solid support characterization}

The FE-SEM image of synthesized magnetite nanoparticles is shown in the Figure 1. From the figure, $\mathrm{Fe}_{3} \mathrm{O}_{4}$ nanoparticles and nano- $\mathrm{Fe}_{3} \mathrm{O}_{4} @$ Cyanuric Chloride have spherical shape with average size of 30-40 and 40-60 nm, respectively.

Figure 2 shows the thermal gravimetry analysis curves (TGA) of $\mathrm{Fe}_{3} \mathrm{O}_{4}$ and nano- $\mathrm{Fe}_{3} \mathrm{O}_{4} @$ Cyanuric Chloride, respectively. In samples there is an insignificant weight loss stage (below $130^{\circ} \mathrm{C}$ ) that can be imputed to the evaporation of water and ethanol. In addition in modified sample, weight loss started at 200 to $700^{\circ} \mathrm{C}$ and correspondent to the thermal decomposition of (Cyanuric Chloride) coating on magnetite nanoparticles. Actually weight loss, the coated Cyanuric Chloride on the surface $\mathrm{Fe}_{3} \mathrm{O}_{4}$ NPs is calculated as $12 \%$.

Modification of magnetite nanoparticle with Cyanuric Chloride was confirmed by FT-IR spectroscopy (Figure 3). The vibrations at $400 \mathrm{~cm}^{-1}$ and $580 \mathrm{~cm}^{-1}$ are attributed to the Fe-O functional groups of magnetite nanoparticle. The vibrations at $810 \mathrm{~cm}^{-1}, 1066 \mathrm{~cm}^{-1}$ and $1634 \mathrm{~cm}^{-1}$ refer to $\mathrm{C}-\mathrm{Cl}, \mathrm{C}-\mathrm{N}$ and $\mathrm{C}=\mathrm{N}$ respectively. The vibrations at $3400-3600 \mathrm{~cm}^{-1}$ are attributed to adsorbed $\mathrm{O}-\mathrm{H}$ by $\mathrm{Fe}_{3} \mathrm{O}_{4}$.

\subsection{Depolymerization reaction}

Figure 4 shows the reaction scheme of TPA recovery. In this scheme, waste PET flakes received from used bottles were glycolysis in the present nano- $\mathrm{Fe}_{3} \mathrm{O}_{4} @$ Cyanuric Chloride as the solid support and $\mathrm{NaOH}$ as the reagent, by the formation of highly reactive PET- Iron Oxide complex. Further neutralization of unreacted sodium hydroxides and disodium-TPA salts by hydrochloric acid, TPA crystals was obtained.

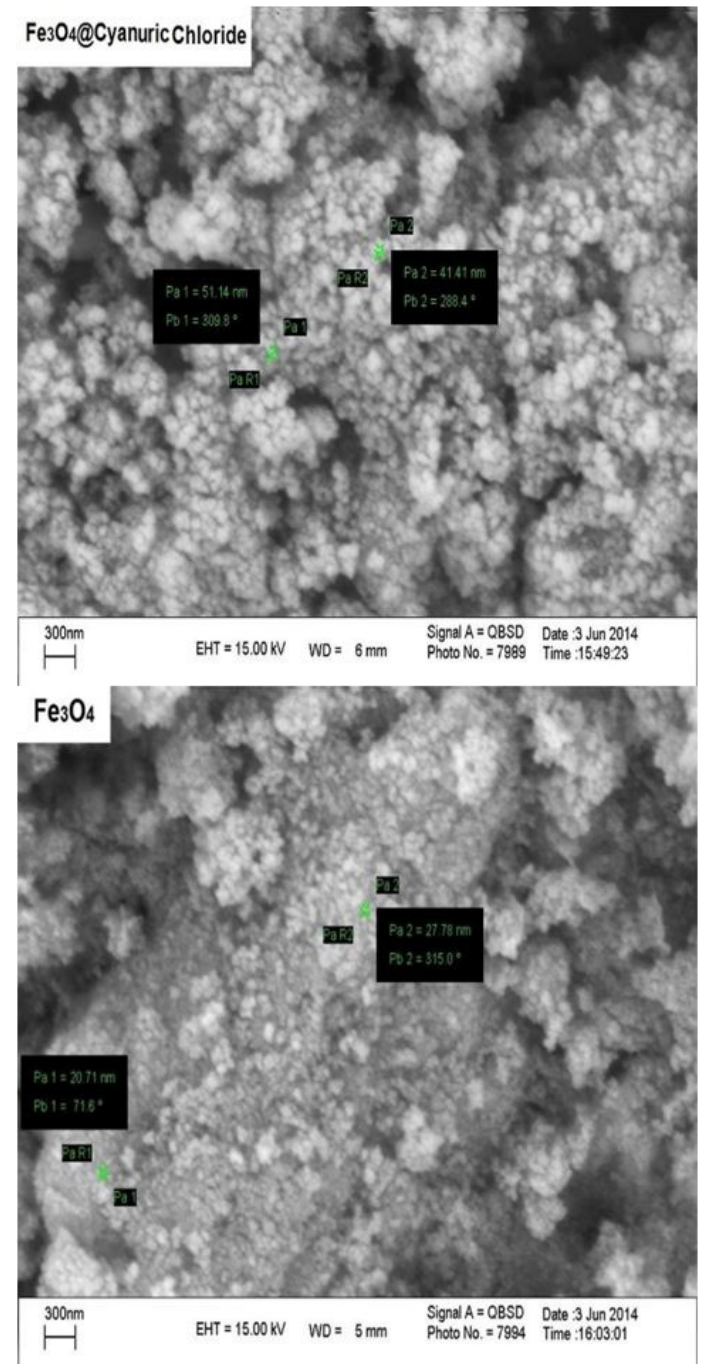

Figure 1. FE-SEM image of synthesized $\mathrm{Fe}_{3} \mathrm{O}_{4}$ and nano- $\mathrm{Fe}_{3} \mathrm{O}_{4} @$ Cyanuric Chloride.

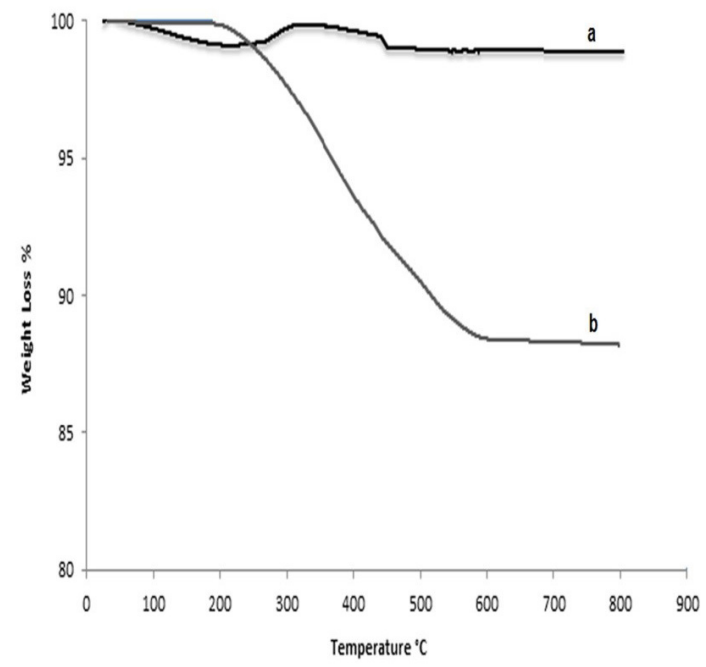

Figure 2. TGA curves for a: $\mathrm{Fe}_{3} \mathrm{O}_{4}$ and b: $\mathrm{Fe}_{3} \mathrm{O}_{4} @$ Cyanuric Chloride nanoparticles. 


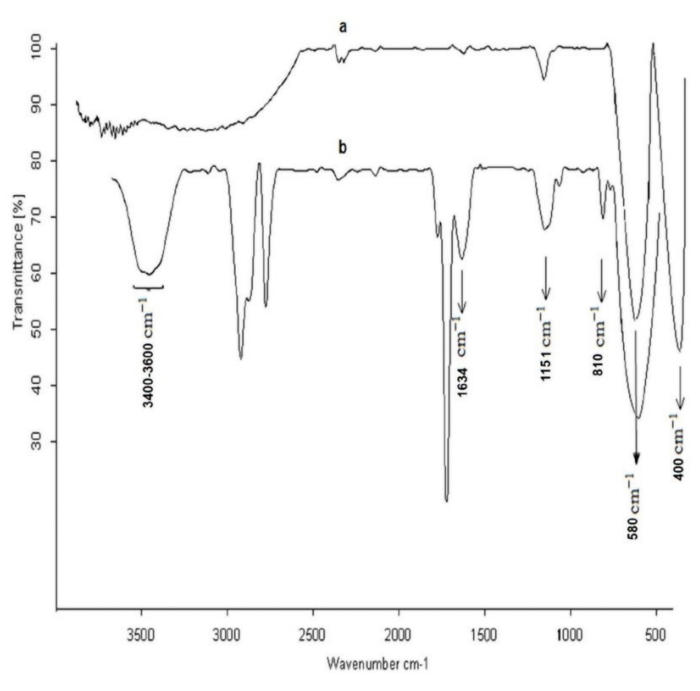

Figure 3. FT-IR spectra of a: $\mathrm{Fe}_{3} \mathrm{O}_{4}$ and b:nano- $\mathrm{Fe}_{3} \mathrm{O}_{4} @$ Cyanuric Chloride.

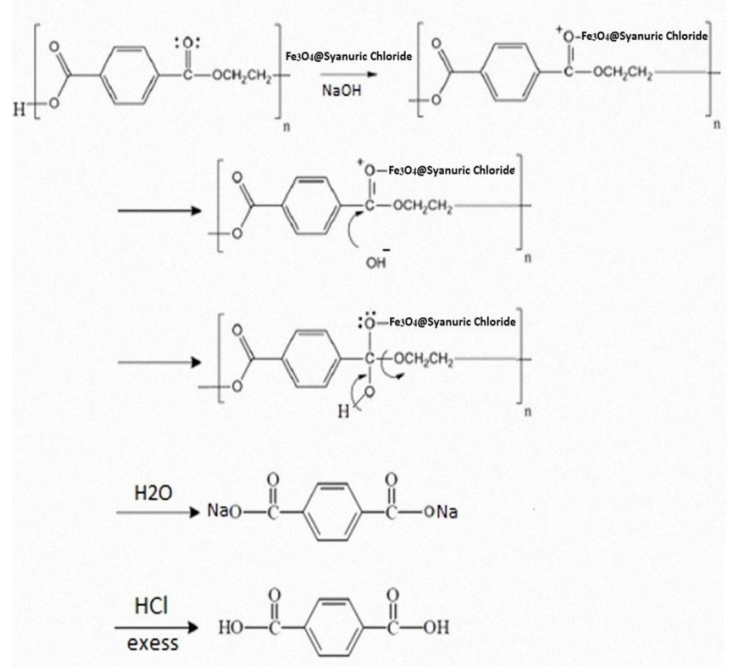

Figure 4. Proposed mechanism for PET glycolysis reaction in the presence of $\mathrm{NaOH}$ as the catalyst and nano- $\mathrm{Fe}_{3} \mathrm{O}_{4} @$ Cyanuric Chloride as the solid support.

\subsection{The role of reagent-solid support on TPA recovery}

The results of performance of nano- $\mathrm{Fe}_{3} \mathrm{O}_{4} @$ Cyanuric Chloride as solid support in recovering of TPA collected in Figure 5 and Tables 1-3, respectively and data were compared with our previously reported data without using this solid support ${ }^{[5]}$. In the present of nano- $\mathrm{Fe}_{3} \mathrm{O}_{4} @$ Cyanuric Chloride $(0.02 \mathrm{~g})$ the required recovery time to access high recovery yield decreases up $99 \%$ which is comparable with microwave conducted reaction (Table 1). This can be related to the nano- $\mathrm{Fe}_{3} \mathrm{O}_{4} @$ Cyanuric Chloride capability to increase surface area rendering more active sites and thermal stability.

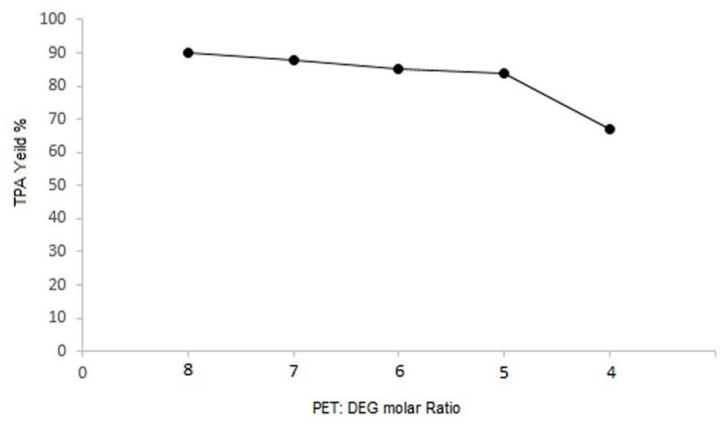

Figure 5. The effect of PET: DEG molar ratios on the glycolysis of PET in the present of $\mathrm{Fe}_{3} \mathrm{O}_{4} @$ Cyanoric Chloride (0.02 g) and $\mathrm{NaOH}(0.30 \mathrm{~g})$.

Table 1. The effect of time on the glycolysis of PET in the present of $\mathrm{Fe}_{3} \mathrm{O}_{4} @$ Cyanoric Chloride.

\begin{tabular}{ccccc}
\hline Entry & $\begin{array}{c}\mathbf{F e}_{3} \mathbf{O}_{\mathbf{4}} \text { @Cyanoric } \\
\text { Chloride } \\
(\mathbf{g})\end{array}$ & $\begin{array}{c}\text { Time } \\
(\mathbf{m i n})\end{array}$ & $\begin{array}{c}\text { Unreacted } \\
\text { PET } \\
(\mathbf{g})\end{array}$ & $\begin{array}{c}\text { TPA } \\
\text { yield } \\
\mathbf{\%}\end{array}$ \\
\hline $\mathbf{1}$ & 0.00 & 101 & 0.00 & 90 \\
$\mathbf{2}$ & 0.02 & 101 & 0.00 & 95 \\
$\mathbf{3}$ & 0.02 & 50 & 0.00 & 94 \\
$\mathbf{4}$ & 0.02 & 30 & 0.00 & 90 \\
$\mathbf{5}$ & 0.02 & 20 & 0.00 & 90 \\
$\mathbf{6}$ & 0.02 & 15 & 0.00 & 92 \\
$\mathbf{7}$ & 0.02 & 10 & 0.00 & 91 \\
$\mathbf{8}$ & 0.02 & 5 & 0.00 & 90 \\
$\mathbf{9}$ & 0.02 & 2 & 0.00 & 89 \\
$\mathbf{1 0}$ & 0.02 & 1 & 0.00 & 87 \\
$\mathbf{1 1}$ & 0.02 & 0.5 & 0.32 & 54 \\
\hline
\end{tabular}

Table 2. The effect of solid supported catalyst concentration on the glycolysis of PET $(1 \mathrm{~g})$ in the present of $\mathrm{NaOH}(0.5 \mathrm{~g})$ and DEG $(7 \mathrm{~mL})$.

\begin{tabular}{ccc}
\hline Entry & $\begin{array}{c}\mathbf{F e}_{3} \mathbf{O}_{4} @ \begin{array}{c}\text { Cyanoric Chloride } \\
(\mathbf{g})\end{array} \\
\mathbf{T}\end{array}$ & $\begin{array}{c}\text { TPA yield } \\
\mathbf{\%}\end{array}$ \\
\hline $\mathbf{2}$ & 0.01 & 77 \\
$\mathbf{3}$ & 0.02 & 87 \\
$\mathbf{4}$ & 0.03 & 88 \\
$\mathbf{5}$ & 0.05 & 87 \\
$\mathbf{6}$ & 0.08 & 88 \\
$\mathbf{7}$ & 0.10 & 84 \\
$\mathbf{8}$ & 0.20 & 82 \\
\hline
\end{tabular}

The results of changing concentration of nano- $\mathrm{Fe}_{3} \mathrm{O}_{4} @$ Cyanuric Chloride are collected in Table 2. In entry 2 maximum amount of terephthalic acid yield $(87 \%)$ was obtained, that is related to presence of nano- $\mathrm{Fe}_{3} \mathrm{O}_{4} @$ Cyanuric Chloride $(0.02 \mathrm{~g})$ in the reaction mixture.

In order to studying of catalyst role, six sets of reactions were handled in the same reaction times and data collected in the Table 3. As shown on entry 4 of Table 3, by decreasing $\mathrm{NaOH}$ concentration to $40 \%$ sightly value of reaction (entry 1 ), the TPA recovery yield will remain constant. 
Table 3. The effect of catalyst concentration on the glycolysis of PET $(1 \mathrm{~g})$.

\begin{tabular}{ccccc}
\hline Entry & $\begin{array}{c}\mathrm{Fe}_{3} \mathbf{O}_{\mathbf{4}} @ \\
\text { Cyanoric } \\
\text { Chloride } \\
(\mathbf{g})\end{array}$ & $\begin{array}{c}\mathbf{N a O H} \\
(\mathbf{g})\end{array}$ & $\begin{array}{c}\text { Unreacted } \\
\text { PET } \\
(\mathbf{g})\end{array}$ & $\begin{array}{c}\text { TPA yield } \\
\mathbf{\%}\end{array}$ \\
\hline $\mathbf{1}$ & 0.00 & 0.50 & 0.00 & 90 \\
$\mathbf{2}$ & 0.02 & 0.50 & 0.00 & 95 \\
$\mathbf{3}$ & 0.02 & 0.40 & 0.00 & 89 \\
$\mathbf{4}$ & 0.02 & 0.30 & 0.00 & 87 \\
$\mathbf{5}$ & 0.02 & 0.20 & 0.21 & 53 \\
$\mathbf{6}$ & 0.02 & 0.10 & 0.52 & 34 \\
\hline
\end{tabular}

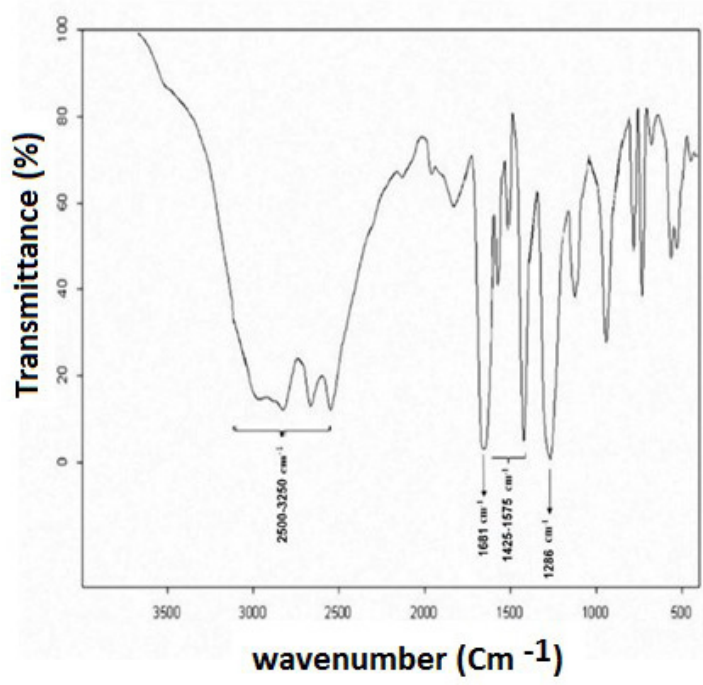

Figure 6. FT-IR spectra of obtained TPA from Glycolysis.

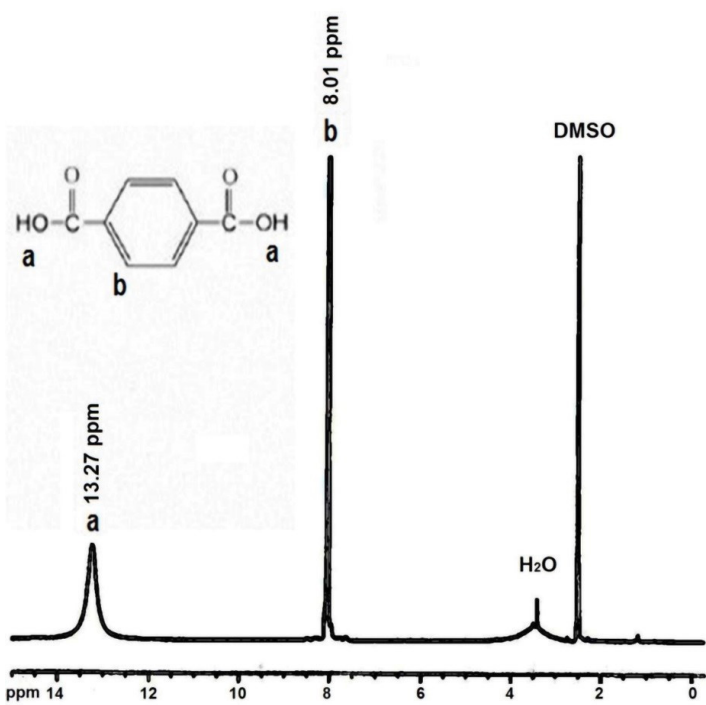

Figure 7. ${ }^{1} \mathrm{HNMR}$ spectra of obtained TPA from Glycolysis.



Figure 8. ${ }^{13} \mathrm{CNMR}$ spectra of obtained TPA from Glycolysis.

In order to finding the optimum PET: DEG molar ratios, we decrease this ratio (Figure 5). As shown in this figure, in present of nano- $\mathrm{Fe}_{3} \mathrm{O}_{4} @$ Cyanuric Chloride (0.02 g) and by altering PET: DEG molar ratios from $1: 8$ to $1: 5$, the slight decrements in TPA recovery yield are observed and suddenly drop in 1:4 molar ratio. And this means we have $37.5 \%$ saving energy.

\subsection{IR spectroscopy analysis of obtained TPA}

Figure 6 shows IR Spectroscopy of obtained TPA from glycolysis reaction. Specifications bond at $2500-3250 \mathrm{~cm}^{-1}$ are related to carboxylic group, $1685 \mathrm{~cm}^{-1}$ are related to carbonyl group and $1574-1425 \mathrm{~cm}^{-1}$ are related to aromatic ring. These results have a good match with the reference data related to virgin TPA showing that the purity of the product in this method is passable.

\section{$3.5^{1} H N M R$ analysis}

Figure 7 shows ${ }^{1} \mathrm{HNMR}$ spectrum of obtained TPA. The revealed bands at $8.01 \mathrm{ppm}$ and $13.27 \mathrm{ppm}$ are related to protons of aromatic ring and acidic proton respectively and spectrum is similar to the authentic sample one.

\section{6 ${ }^{13} \mathrm{CNMR}$ analysis}

Figure 8 shows ${ }^{13} \mathrm{CNMR}$ spectrum of obtained TPA. The revealed band at $167.10 \mathrm{ppm}$ are related to carbon of carbonyl group and $129.93 \mathrm{ppm}$ and $134.86 \mathrm{ppm}$ are related to carbons of aromatic ring and all signals math with an authentic sample spectrum signal.

\section{Conclusion}

In conclusion, nano- $\mathrm{Fe}_{3} \mathrm{O}_{4} @$ Cyanuric Chloride can be used as the effective supported catalyst in recovering of terephthalic acid from PET wastes in combination with sodium hydroxide. The obtained results from the glycolysis of PET wastes by using DEG as the solvent, sodium hydroxide as the reagent and nano- $\mathrm{Fe}_{3} \mathrm{O}_{4} @$ Cyanuric Chloride as the reagent-solid support led to successful recovering of TPA 
in high yields. In the presences of nano- $\mathrm{Fe}_{3} \mathrm{O}_{4} @$ Cyanuric Chloride, the required reaction time for TPA recovery, DEG and $\mathrm{NaOH}$ consumptions decrease about $99,37.5$ and $40 \%$, respectively.

\section{Acknowledgements}

The authors thank Imam Khomeini International University (IKIU) for the financial support of Dr. Alavi Nikje.

\section{References}

1. Nikje, M. M. A., Nazari, F., Imanieh, H., Garmarudi, A. B., \& Haghshenas, M. (2007). PET recycling by diethylene glycoldiethanol amine binary mixture and application of product in rigid polyurethane foam formulation. Journal of Macromolecular Science, Part A: Pure and Applied Chemistry, 44(7), 753-758. http://dx.doi.org/10.1080/10601320701353231.

2. Siddiqui, M. N., Redhwi, H. H., \& Achilias, D. S. (2012). Recycling of poly(ethylene terephthalate) waste through methanolic pyrolysis in a microwave reactor. Journal of Analytical and Applied Pyrolysis, 98, 214-220. http://dx.doi. org/10.1016/j.jaap.2012.09.007.

3. Nikje, M. M. A., \& Nazari, F. (2006). Microwave-assisted depolymerization of Poly(ethylene terephthalate) [PET] at atmospheric pressure. Advances in Polymer Technology, 25(4), 242-246. http://dx.doi.org/10.1002/adv.20080.

4. Pingale, N. D., \& Shukla, S. R. (2008). Microwave assisted ecofriendly recycling of poly (ethylene terephthalate) bottle waste. European Polymer Journal, 44(12), 4151-4156. http:// dx.doi.org/10.1016/j.eurpolymj.2008.09.019.

5. Nikje, M. M. A., \& Nazari, F. (2009). Simple and convenient method of chemical recycling of poly (ethylene terephthalate) by using microwave radiation. Polimery, 54(9), 635-639. Retrieved in 2015, July 07, from http://www.ichp.pl/attach. php?id=244

6. Parab, Y. S., Shah, R. V., \& Shukla, S. R. (2012). Microwave irradiated synthesis and characterization of 1, 4-phenylene bis-oxazoline form bis-(2-hydroxyethyl) terephthalamide obtained by depolymerization of poly (ethylene terephthalate) (PET) bottle wastes. Current Chemistry Letters, 1(2), 81-90. http://dx.doi.org/10.5267/j.ccl.2012.3.003.

7. Chen, F., Wang, G., Shi, Ch., Zhang, Y., Zhang, L., Li, W., \& Yang, F. (2013). Kinetics of glycolysis of poly (ethylene terephthalate) under microwave irradiation. Journal of Applied Polymer Science, 127(4), 2809-2815. http://dx.doi.org/10.1002/ app.37608

8. Rusen, E., Mocanu, A., Rizea, F., Diacon, A., Calinescu, I., Mititeanu, L., Dumitrescu, D., \& Popa, A.-M. (2013). Postconsumer PET Bottles Recycling II. PET depolymerization using microwaves. Materiale Plastice, 50(3), 201-207. Retrieved in 2015, July 07, from http://www.revmaterialeplastice.ro/pdf/ RUSEN\%20E.pdf\%203\%2013.pdf

9. Chaudhary, S., Surekha, P., Kumar, D., Rajagopal, C., \& Roy, P. K. (2013). Microwave assisted glycolysis of poly(ethylene terephthalate) for preparation of polyester polyols. Journal of Applied Polymer Science, 129(5), 2779-2788. http://dx.doi. org/10.1002/app.38970.

10. Liu, N., Ma, Y., Shu, K., Wu, B., \& Zhang, D. (2014). Catalysis investigation of PET depolymerization with bransted acidic ionic liquid under microwave irradiation. Advanced Materials Research, 893, 23-29. http://dx.doi.org/10.4028/www.scientific. net/AMR.893.23

11. Yue, F. Q., Yang, H. G., Zhang, L. M., \& Bai, X. F. (2014) Metal-Containing ionic liquids: highly effective catalysts for degradation of poly(Ethylene Terephthalate). Advances in Materials Science and Engineering, 2014, 1-6. http://dx.doi. org/10.1155/2014/454756.

12. Yue, Q. F., Wang, C. X., Zhang, L. N., Ni, Y., \& Jin, Y. X (2011). Glycolysis of poly(ethylene terephthalate) (PET) using basic ionic liquids as catalysts. Polymer Degradation \& Stability, 96(4), 399-403. http://dx.doi.org/10.1016/j. polymdegradstab.2010.12.020.

13. Aguado, A., Martínez, L., Becerra, L., Arieta-araunabena, M., Arnaiz, S., Asueta, A., \& Robertson, I. (2014). Chemical depolymerization of PET complex waste: hydrolysis vs. glycolysis. Journal of Material Cycles and Waste Management, 16(2), 201-210. http://dx.doi.org/10.1007/s10163-013-0177-y.

14. Imran, M., Lee, K. G., Imtiaz, Q., Kim, Q. B., Han, M., Cho, B. G., \& Kim, D. (2011). Metal-oxide-doped silica nanoparticles for the catalytic glycolysis of polyethylene terephthalate. Journal of Nanoscience and Nanotechnology, 11(1), 824-828. PMid:21446554. http://dx.doi.org/10.1166/jnn.2011.3201.

15. Wi, R., Imran, M., Lee, K. G., Yoon, S. H., Cho, B. G., \& Kim, D. H. (2011). Effect of support size on the catalytic activity of metal-oxide-doped silica particles in the glycolysis of polyethylene terephthalate. Journal of Nanoscience and Nanotechnology, 11(7), 6544-6549. PMid:22121753. http:// dx.doi.org/10.1166/jnn.2011.4393.

16. Park, G., Bartolome, L., Lee, K. G., Lee, S. J., Kim, D. H., \& Park, T. J. (2012). One-step sonochemical synthesis of a graphene oxide-manganese oxide nanocomposite for catalytic glycolysis of poly(ethylene terephthalate). Nanoscale, 4(13), 3879-3885. PMid:22592889. http://dx.doi.org/10.1039/ c2nr30168g.

17. Bartolome, L., Imran, M., Lee, G. K., Sangalang, A., Ahn, K. J., \& Kim, D. H. (2013). Superparamagnetic $\gamma-\mathrm{Fe}_{2} \mathrm{O}_{3}$ nanoparticles as an easily recoverable catalyst for the chemical recycling of PET. Green Chemistry, 16(1), 279-286. http:// dx.doi.org/10.1039/C3GC41834K.

18. Balacianu, F. D., Nechifor, A. C., Bartos, R., Voicu, S. I., \& Nechifor, G. (2009). Synthesis and characterization of $\mathrm{Fe}_{3} \mathrm{O}_{4}$ magnetic particles-multiwalled carbon nanotubes by covalent functionalization. Optoelectronics and Advanced Materials Rapid Communications, 3(3), 219-222. Retrieved in 2015, July 07 , from https://oam-rc.inoe.ro/download.php?idu=665

Received: July 07, 2015

Revised: Mar. 21, 2016

Accepted: June 10, 2016 